\title{
EVALUATION OF A PARAMETRIC-TYPE WAVE TRANSFORMATION MODEL AGAINST FIELD AND LABORATORY DATA
}

\author{
Alireza Jafari ${ }^{1}$ and Nick Cartwright ${ }^{1}$
}

Predicting wave properties via parametric wave propagation models are broadly used in many coastal engineering applications. Numerous researchers have refined these types of models to increase their accuracy including; Battjes and Janssen (1978), Thornton and Guza (1983), Baldock et al. (1998), and Alsina and Baldock (2007). Alsina and Baldock (2007), proposed an improved parametric wave propagation models for a non-saturated surfzone which returns relatively more accuracy in comparison to others. In this paper, the Alsina and Baldock (2007) model along with Baldock et al. (1998) and Thornton and Guza (1983), are applied to data collected in South-East Queensland under stormy and calm conditions as well as laboratory data. Some of the comparisons indicate the need to incorporate some additional energy loss at the break point to account for plunging type breakers where the existing bore dissipation model is insufficient.

Keywords: Wave transformation model; surfzone hydrodynamics; wave energy dissipation; field data; storm condition

\section{INTRODUCTION}

Parametric wave propagation models are broadly used in many coastal engineering applications. Depending on the parameter fitting, they mainly reflect $80 \%-85 \%$ accuracy, which is desirable in most coastal area problems (Ruessink et al., 2003; van Rijna et al., 2003). However, errors in wave prediction normally add up the amount of computation errors in hydrodynamic related parameters such as wave set up, sediment transport, and radiation stress (Guard and Baldock, 2007). Therefore, numerous researchers have put effort into this issue to increase the accuracy of parametric wave propagation models (e.g. Alsina and Baldock, 2007; Baldock et al., 1998; Battjes and Janssen, 1978; Ruessink et al., 2003; Thornton and Guza, 1983). Alsina and Baldock(2007) proposed a modified form of the parametric wave propagation model for non-saturated surfzone based on Baldock et al. (1998). However, they presented the results against laboratory data. In the present papert, Alsina and Baldock's (2007) model, hereafter referred to asAB07, is applied to data collected in South-East Queensland under stormy and calm conditions (Jafari et al., 2011), as well as laboratory data. Meanwhile, the model of Thornton and Guza (1983), hereafter referred to as TG83, and also Baldock et al. (1998), hereafter referred to as $\mathrm{B} 98$, were compared to the $\mathrm{AB} 07$ results.

\section{PARAMETRIC WAVE MODELS}

Battjes and Janssen (1978) took the very first step in this field and introduced their pioneer model which later modified and refined by others (e.g. TG83, B98, and AB07). Parametric models evaluate the wave height across the surfzone using energy flux equilibrium,

$$
\frac{\partial\left(E C_{g}\right)}{\partial x}=-D_{E}
$$

where, $C_{g}$ and $\mathrm{E}$ are respectively the group velocity and wave energy which can be estimated using linear wave theory,

$$
\begin{gathered}
E=\frac{1}{8} \rho g H_{r m s}^{2} \\
C_{\mathrm{g}}=C \frac{1}{2}\left(1+\frac{2 k h}{\sinh 2 k h}\right) \cos \theta
\end{gathered}
$$

where $\rho$ is water density, $C$ is wave phase velocity, $k$ is wave number, $h$ is water depth, and $\theta$ is approaching wave angle. $D_{E}$ denotes time averaged wave energy dissipation. In parametric models for determining $D_{E}$, primarily, bore dissipation, $D_{B}$, and secondarily dissipation due to bottom friction, $D_{f}$, are considered (Thornton and Guza, 1983; Baldock et al., 1998; Alsina and Baldock, 2007).

$$
D_{E}=D_{B}+D_{f}
$$

\footnotetext{
${ }^{1}$ Griffith School of Engineering, Gold Coast Campus, Griffith University, QLD 4222, Australia, (a.jafari@griffith.edu.au \&n.cartwright@griffith.edu.au)
} 


\section{Bore Dissipation Model}

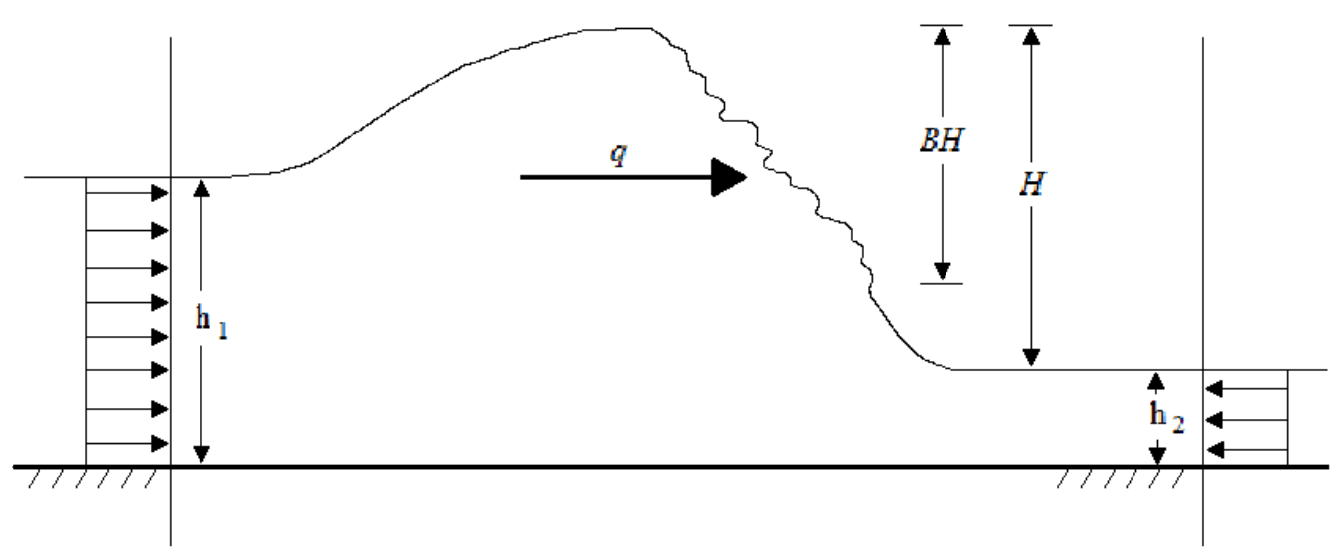

Figure 1. Schematic sketch of wave energy dissipation

As a result of the wave breaking, the wave crest generally curls over and generates vortices at the water surface. The dissipation rate due to breaking depends on the size and strength of these vortices (Battjes and Janssen, 1978). The turbulence on the spilling breaker, qualitatively, is similar to a bore and can be treated as a travelling hydraulic jump (Thornton and Guza, 1983). By applying the conservation of mass and momentum on the control volume shown in Figure 1, where the boundaries are located at uniform flows both upstream and downstream, the details associated with the turbulence itself can be avoided. Hence, the average bore dissipation per unit area can be determined by (LeMehaute, 1962),

$$
D_{B}=\frac{1}{4} \rho g \frac{\left(h_{2}-h_{1}\right)^{3}}{h_{2} h_{1}} q \approx \frac{1}{4} \rho g \frac{(B H)^{3}}{h^{2}} q
$$

where, $H$ is the wave height, $q$ is the volume discharge per unit width across the bore, and $B$ is a factor describing the ration of foam region over total wave height. For a linear periodic bore, $q$ can be defined as ratio of phase velocity times water depth over wave length (Hwang and Divoky, 1970),

$$
q=\frac{C h}{L}=f_{p} h
$$

where, $f_{p}$ is peak frequency. Substituting equation (6) back into equation (5) gives the bore dissipation for a single breaking wave as follows,

$$
D_{B}=\frac{1}{4} \rho g f_{p} \frac{(B H)^{3}}{h}
$$

\section{Bore dissipation model applied to a wave distribution}

In order to obtain the average bore energy dissipation for a distribution of irregular waves, equation (7)needs to be multiplied by the number of breaking waves in the distribution. By integrating the product of equation (7) and the probability density function, pdf, of the ratio of breaking waves over the total number of waves (see Figure 2), parametric models evaluate the energy dissipation and wave transformation across the surfzone. The main difference between the various models rises from determining the fraction of breaking waves in an irregular sea wave state. 


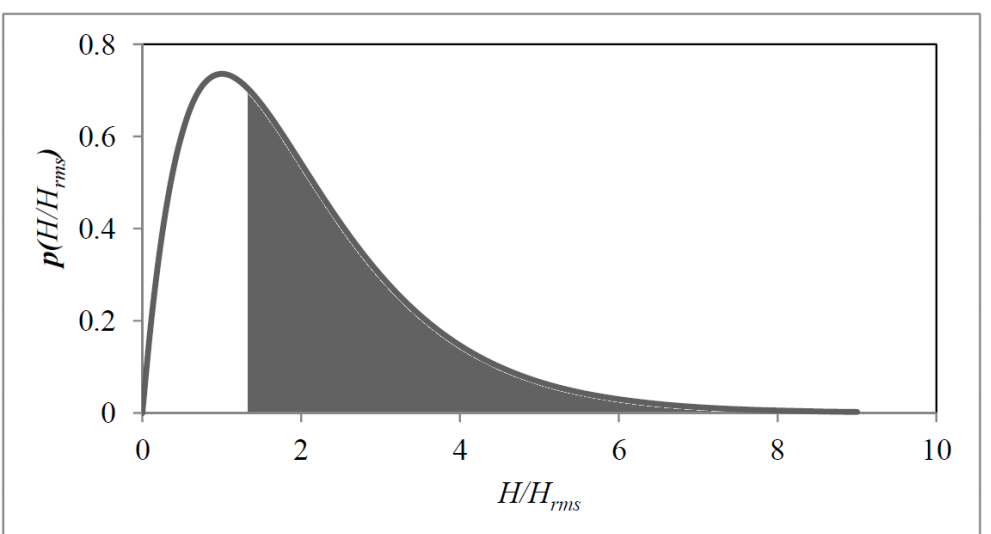

Figure 2.Theoretical Rayleigh distribution of wave height (solid line) and breaking wave height distribution (shaded are) where $H / H_{r m s} \geq H_{b} / H_{r m s}$

After Batttjes and Janssen (1978),TG83 proposed an empirical weighted Rayleigh distribution, based on field data recorded from Torrey Pines beach,

$$
\begin{aligned}
& p_{b}(H)=W(H) p(H)=\left(\frac{H_{r m s}}{\gamma h}\right)^{n} \times \\
& \left\{\frac{2 H}{H_{r m s}^{2}} \exp \left[-\left(\frac{H}{H_{r m s}}\right)^{2}\right]\right\}
\end{aligned}
$$

where, $\gamma$ is the ratio of wave height over water depth and $n$ is a variable determined equal to 4 based on observation. Therefore, by integrating the product of equation (7) and equation (8), TG83 proposed the overall energy dissipation as follows (Thornton and Guza, 1983),

$$
D_{B-T G 83}=\frac{3 \sqrt{\pi}}{16} \rho g f_{p} B^{3} \frac{H_{r m s}{ }^{5}}{\gamma^{2} h^{3}}\left[1-\frac{1}{\left(1+\left(\frac{H_{r m s}}{\gamma h}\right)^{2}\right)^{\frac{5}{2}}}\right]
$$

TG83 needs to be calibrated by means of determining the optimum value of coefficient $B$ via iteration. Consequently, achieving the best results from TG83 is limited to the availability of field data.

B98 obtained the proportion of breaking waves, $Q_{b}$, directly from the Rayleigh distribution. $Q_{b}$ is determined by integrating the Rayleigh distribution over all waves for which $H / H_{r m s} \geq H_{b} / H_{r m s}$ resulting in (Baldock et al., 1998),

$$
\begin{aligned}
& Q_{b}=\int_{H^{*}}^{\infty}\left\{\frac{2 H}{H_{r m s}} \exp \left[-\left(\frac{H}{H_{r m s}}\right)^{2}\right]\right\} d\left(\frac{H}{H_{r m s}}\right) \\
& =\exp \left[-\left(\frac{H_{b}}{H_{r m s}}\right)^{2}\right]
\end{aligned}
$$

where, $H^{*}=H_{b} / H_{r m s}$ and $H_{b}$ is maximum wave height just before breaking. B98 applied Nairn's (1990) expression of $H_{b}$ which is as follows,

$$
\frac{H_{b}}{h}=0.39+0.56 \tanh \left(33 S_{0}\right)
$$

where, $S_{0}$ is offshore wave steepness. B98 assumed that the relationship of $H / h$ in equation (7) is close to 1 . Also, they suggested that factor $B$ can be considered 1 for simplification purposes. Thus, the time averaged rate of energy dissipation proposed by B98 does not assume prior knowledge of the surfzone condition, which is given by (Baldock et al., 1998),

$$
\begin{aligned}
& D_{B-B 98}=\frac{1}{4} \rho g f_{p} B \exp \left[-\left(\frac{H_{b}}{H_{r m s}}\right)^{2}\right] \\
& \times\left(H_{b}{ }^{2}+H_{r m s}{ }^{2}\right)
\end{aligned}
$$


AB07 followed the B98 approaches. They considered the Rayleigh distribution for evaluating $Q_{b}$. However,AB07 mentioned that the field and laboratory data presented by Raubenheimer et al. (1996)showed the assumption of considering ratio of $H / h$ equal to 1 is not the case close to shoreline. Hence, the original term of $H^{3} / h$ in equation (7)was retained and AB07 proposed the following bore dissipation formula (Alsina and Baldock, 2007),

$$
\begin{aligned}
& D_{B-A B 07}=\frac{1}{4} \rho g f_{p} B \frac{H_{r m s}^{3}}{h} \times \\
& \left\{\left[\left(\frac{H_{b}}{H_{r m s}}\right)^{3}+\frac{3}{2} \frac{H_{b}}{H_{r m s}}\right] \times\right. \\
& \exp \left[-\left(\frac{H_{b}}{H_{r m s}}\right)^{2}\right]+\frac{3}{4} \sqrt{\pi}\left[1-\operatorname{erf}\left(\frac{H_{b}}{H_{r m s}}\right)\right]
\end{aligned}
$$

where, erf denote the error function.

\section{FIELD DATA - MODEL COMPARISON}

\section{Data collection and analysis}

Field data was collected from a field site located at The Spit on Gold Coast, Australia. The site used an array of permanently deployed manometer tubes in order to observe both time averaged (mean) water levels (MWL) and high frequency pressure fluctuations at 12 locations through the surf zone as shown in Figure 3 (Jafari et al., 2011).

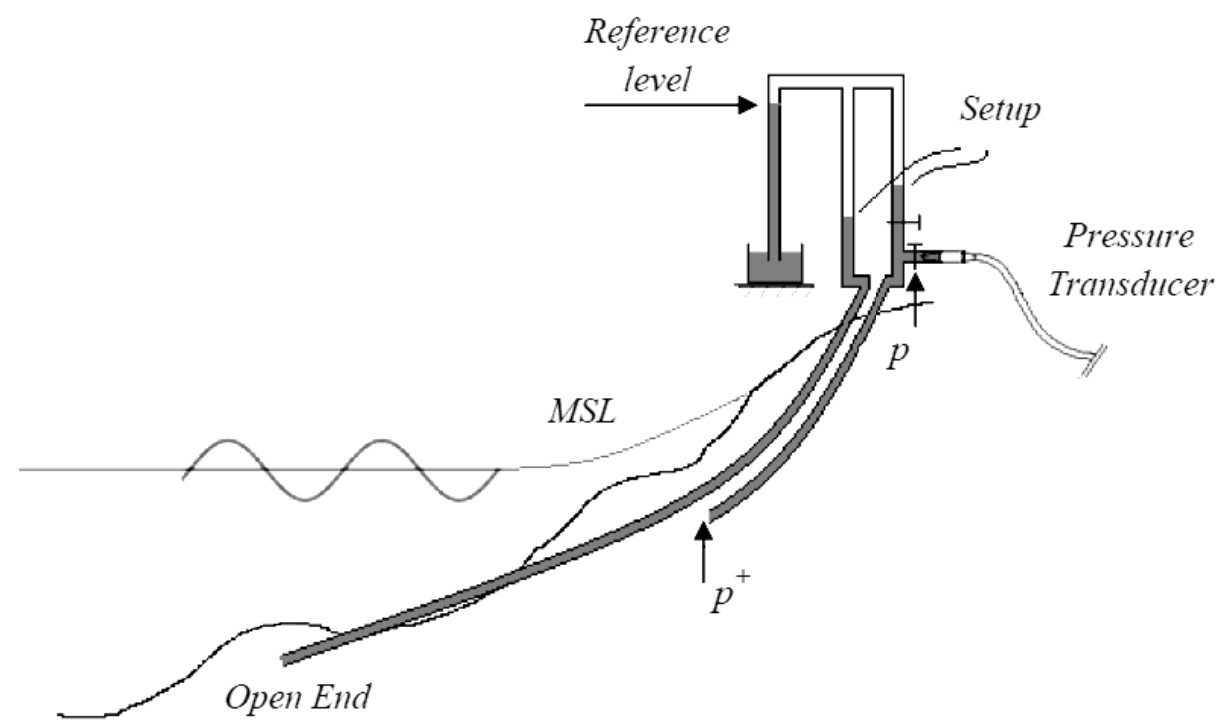

Figure 3. Sketch of the array of the manometer tubes used to record the field data

The setup of the manometer tube system enabled the wave trains to be monitored from $500 \mathrm{~m}$ offshore. The pressure transducer sensors were used to record the high frequency water fluctuation. Wave height could then be calculated by applying a series of equations specified by Jafari et al. (2011) to the recorded signals. The statistics of the wave properties were then computed by the usual methods of spectral analysis and zero-crossing approaches. The bathymetry of each field condition is presented in Figure 4. 

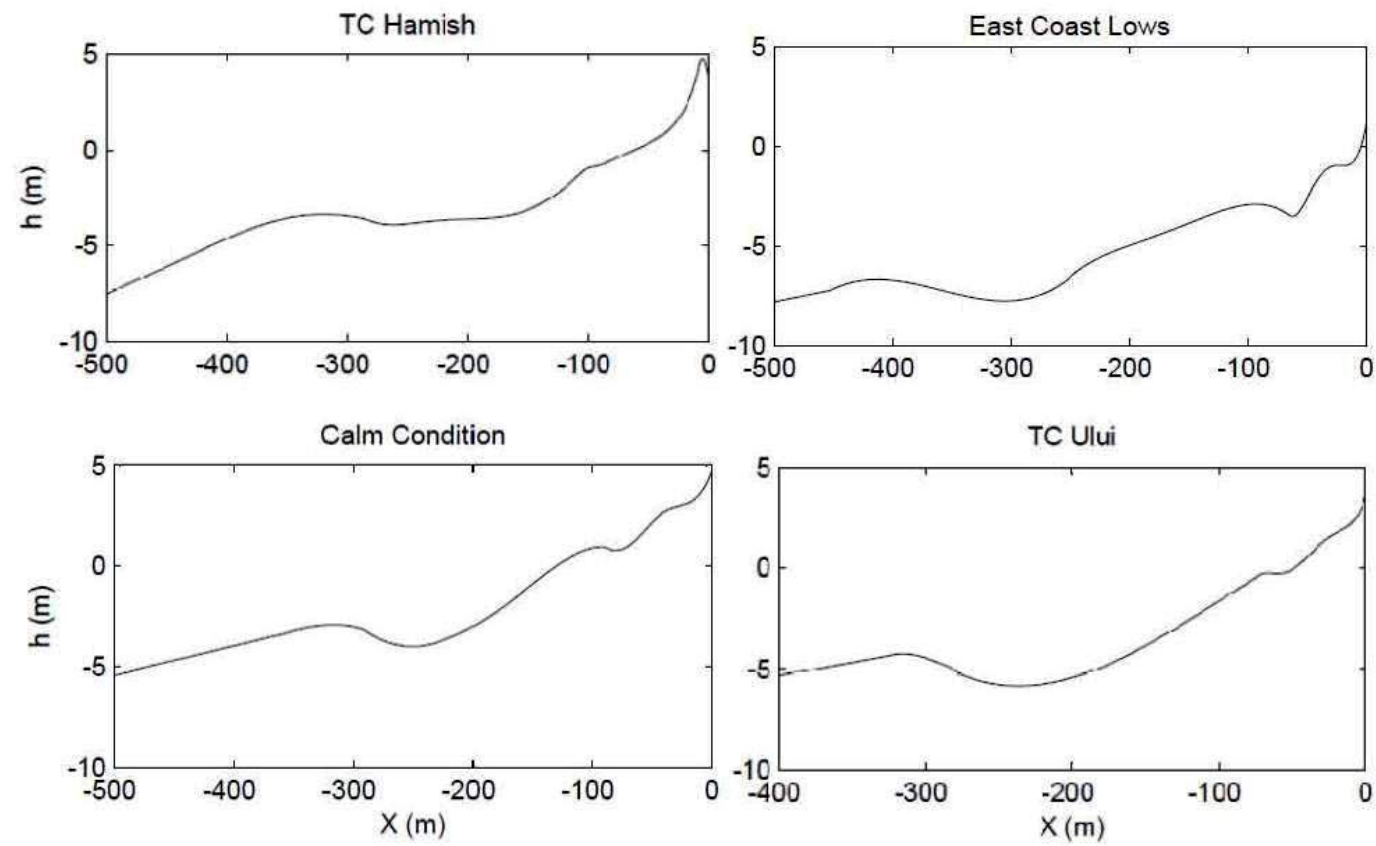

Figure 4. Surfzone bathymetry based on the Australian height datum (AHD) used in the modelling

Consistent with data obtained from the nearby Gold Cost wave rider buoy, the manometer tube wave data was divided into thirty minute time blocks and wave characteristics were extracted using both spectral and zero-crossing approaches. Result are compared and verified against Gold Cost wave rider buoy. The buoy data obtained from the Queensland Department of Environment and Resource Management. Results shows a very good agreement between the recorded data and the buoy data (Jafari et al., 2011). Table 1 presents the field condition and wave statistical data sets used in the comparison against the AB07, B98, and TG83 models. These wave properties are extracted from zero up crossing method. Also these data are just extracted from one block of data sets (thirty minutes of recording). The tide condition of each block of data presented in Figure 5.

In order to fairly evaluate the Rayleigh distribution based models, the recorded data of each event were first analysed to check that they indeed conformed to the Rayleigh distribution. Figure 6 displays the comparison of the recorded data by offshore sensor against Rayleigh distribution for all events. This comparison reveals that the recorded field data do conform to the Rayleigh distribution (the poorest $\mathrm{R}^{2}$ is 0.97 ).

Table 1. Field Condition tested against model prediction, where $S_{\mathrm{o}}$ is offshore wave steepness

\begin{tabular}{cccccccc}
\hline \hline Event & $\begin{array}{c}\text { Offshore Boundary } \\
(\mathrm{m})\end{array}$ & $\begin{array}{c}\text { Offshore Depth } \\
(\mathrm{m})\end{array}$ & $H_{\text {max }}$ & $H_{\text {rmso }}$ & $T_{p}$ & $T_{\text {ave }}$ & $S_{0}$ \\
\hline TC Hamish (11/03/2009) & 500 & 7.6 & 4.8 & 2.3 & 8.2 & 8.2 & 0.022 \\
East Coast Lows (21/05/2009) & 500 & 7.8 & 5.4 & 3.2 & 9.4 & 10.0 & 0.023 \\
East Coast Lows (21/05/2009) & 300 & 5.6 & 2.7 & 1.1 & 9.7 & 12.0 & 0.008 \\
Calm Condition (11/11/2009) & 500 & 5.4 & 0.9 & 0.6 & 7.9 & 7.2 & 0.008 \\
TC Ului (20/03/2010) & 300 & 4.4 & 3.0 & 1.4 & 11.0 & 7.6 & 0.015 \\
\hline
\end{tabular}



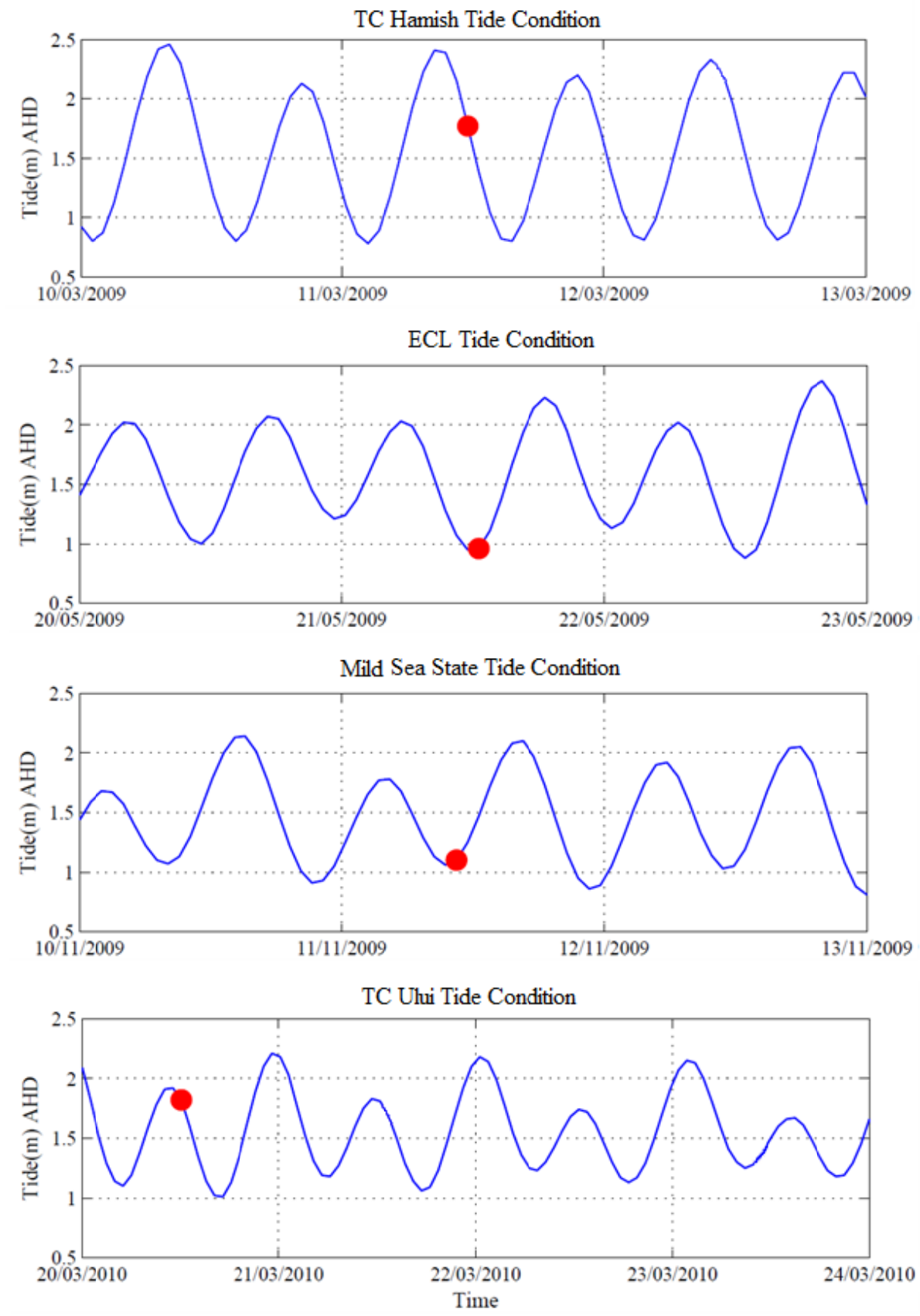

Figure 5. Tide condition for each event that field data were collected

\section{Results and Discussion}

The data-model comparison was quantified based on the coefficient of determination, $\mathrm{R}^{2}$, and error in prediction, $\varepsilon$, as used by Alsina and Baldock (2007) and calculated as follows:

$$
\varepsilon=\frac{1}{N} \frac{\sum \sqrt{\left(H_{\text {comp }}-H_{\text {meas }}\right)^{2}}}{H_{o}}
$$

where, the $N$ is the total number of samples and $H_{o}$ is offshore boundary wave height. Also, $H_{r m s}$, is the statistical wave property that is used in this calculation.

As it depicted in Figure 7 based on calculated $\mathrm{R}^{2}$, and $\varepsilon$, the models prediction of the wave profile across the surfzone is in good agreement with the data of TC Hamish. However, they cannot precisely predict the wave shoaling that took places in recorded data in about $400 \mathrm{~m}$ offshore tube. Then the amount of the energy dissipations calculated by the models (second panel of Figure 7) from 400m 
offshore tube to $300 \mathrm{~m}$ are about half of what the recorded data showed. Also, it should be noted that as TG83 results numerically fit to the data by varying the $B$ coefficient returns slightly better coefficient of determination $\left(\mathrm{R}^{2}\right)$ with data and a bit less error comparing with AB07 and B98.

In East Coast low if the offshore boundary set on $500 \mathrm{~m}$ tube length, the results of the models predictions are over predicted (see Figure 8). The main reason is that the models cannot capture the first breaking point where was happened somewhere around $400 \mathrm{~m}$ offshore. Accordingly, when the $300 \mathrm{~m}$ tube length set as the offshore boundary of the the models, i.e. Figure 9, they still cannot clearly capture the second breaking point; however the results are not over predicted. In both events, TG83 showed better prediction than AB07 and B98 base on the fact that the coefficient factor $B$ in equation (9) should be optimize via recorded data, however it fixed as unity in AB07 and B98. By increasing the value of $B$ coefficient in the dissipation formula, literally, the ratio of the vortices area of the bore to the wave height increases. The $B$ values over one conveys the fact that the ration of vortices penetrated into mean water level below the trough of the wave.

Also, in second panel of Figure 9, which shows the amount of energy dissipation, the TG83 model shows a spike on the shoreline boundaryFigure 8 . Therefore, it conveys that wave breaking occurs on that point which is not the case. Although the TG83 model prediction of stormy events, gives a better correlation with field data due to manipulating the $B$ factor, it didn't physically picture a better result in comparison with B98 and AB07.
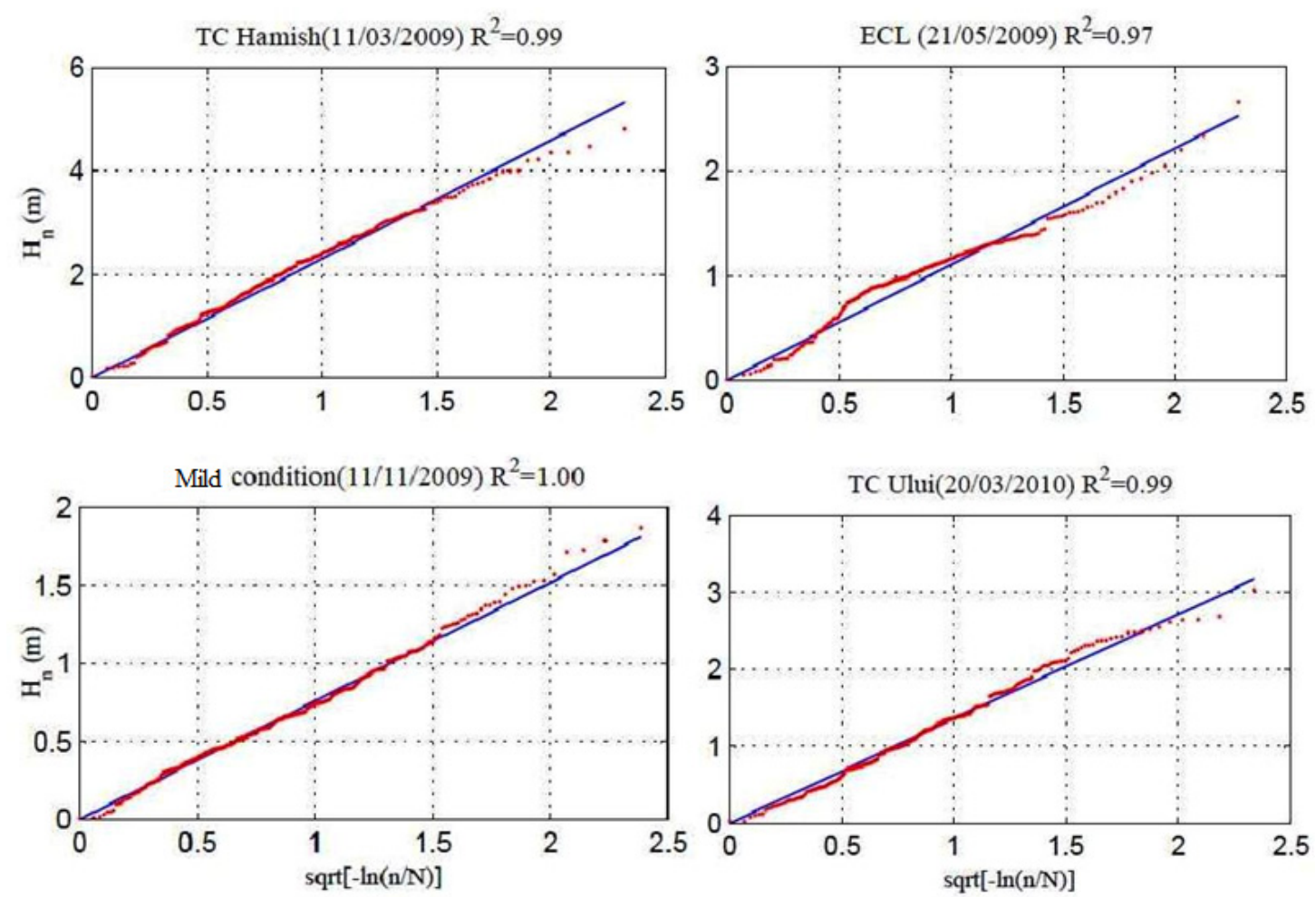

Figure 6. Compare data series of offshore boundaries sensors (from top-left to bottom-right H1, E1-B, C1-B, and $U 1$ ) against Rayleigh distribution. $\mathbf{N}$ is the total number of wave data and $\mathrm{n}$ represent the rank of corresponding wave height sorted from large to small. $\mathbf{R}^{2}$ is Coefficients of determinations between the data and Rayleigh distribution.

As depicted in Figure 10 if the offshore boundary is set on $500 \mathrm{~m}$ offshore in the calm condition data sets, the model results are under predicted. The main reason is that none of the models can accurately evaluate the shoaling which occurs about $400 \mathrm{~m}$ offshore. Also, the value of estimated energy dissipation per meter square by the AB07 and B98 models at second breaking point are almost as half of what really happened in the field. 

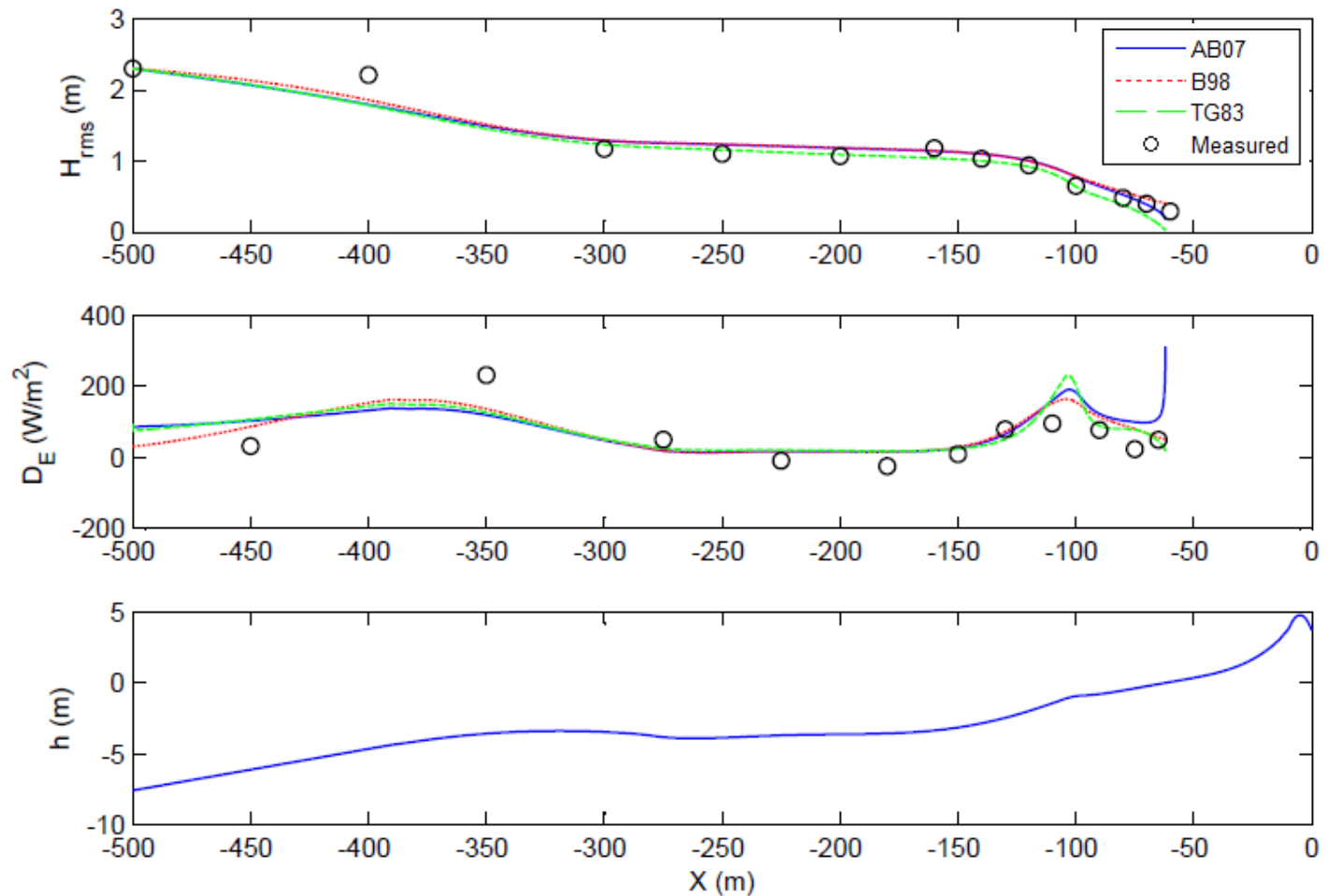

Figure 7. TC Hamish model-data comparison; Top panel is $H_{r m s}$ distribution, 2nd panel is distribution of energy dissipation per unit area and 3rd panel is the bathymetry. Circles represent data; AB07 is the blue line; B98 is the red dotted line and TG83 is the green dash line.
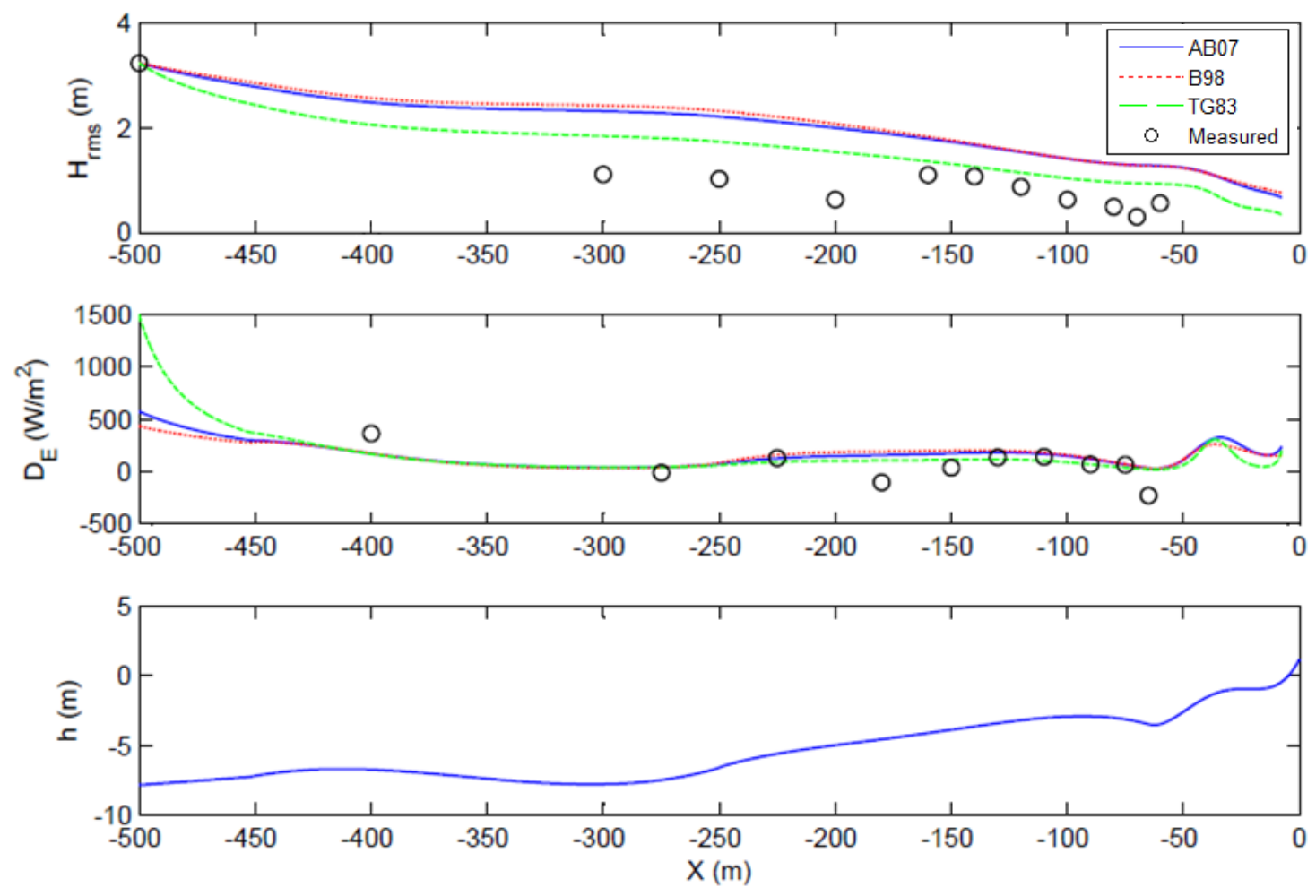

Figure 8. ECL model-data comparison; Top panel is $\boldsymbol{H}_{r m s}$ distribution, 2nd panel is distribution of energy dissipation per unit area and 3rd panel is the bathymetry. Circles represent data; AB07 is the blue line; B98 is the red dotted line and TG83 is the green dash line. 

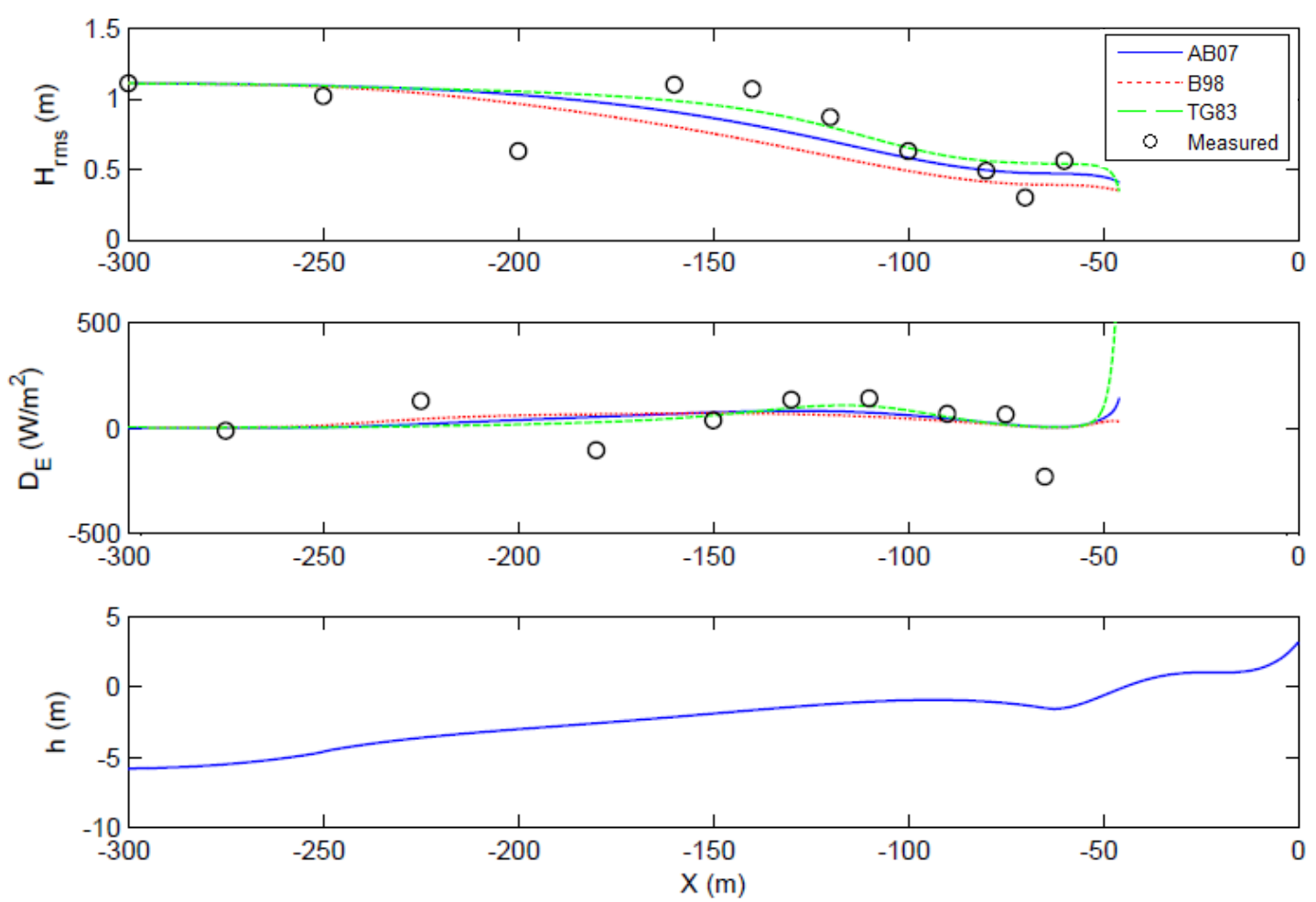

Figure 9. ECL (offshore boundary set as $300 \mathrm{~m}$ ) model-data comparison; Top panel is $\boldsymbol{H}_{r m s}$ distribution, 2nd panel is distribution of energy dissipation per unit area and 3rd panel is the bathymetry. Circles represent data; AB07 is the blue line; B98 is the red dotted line and TG83 is the green dash line.
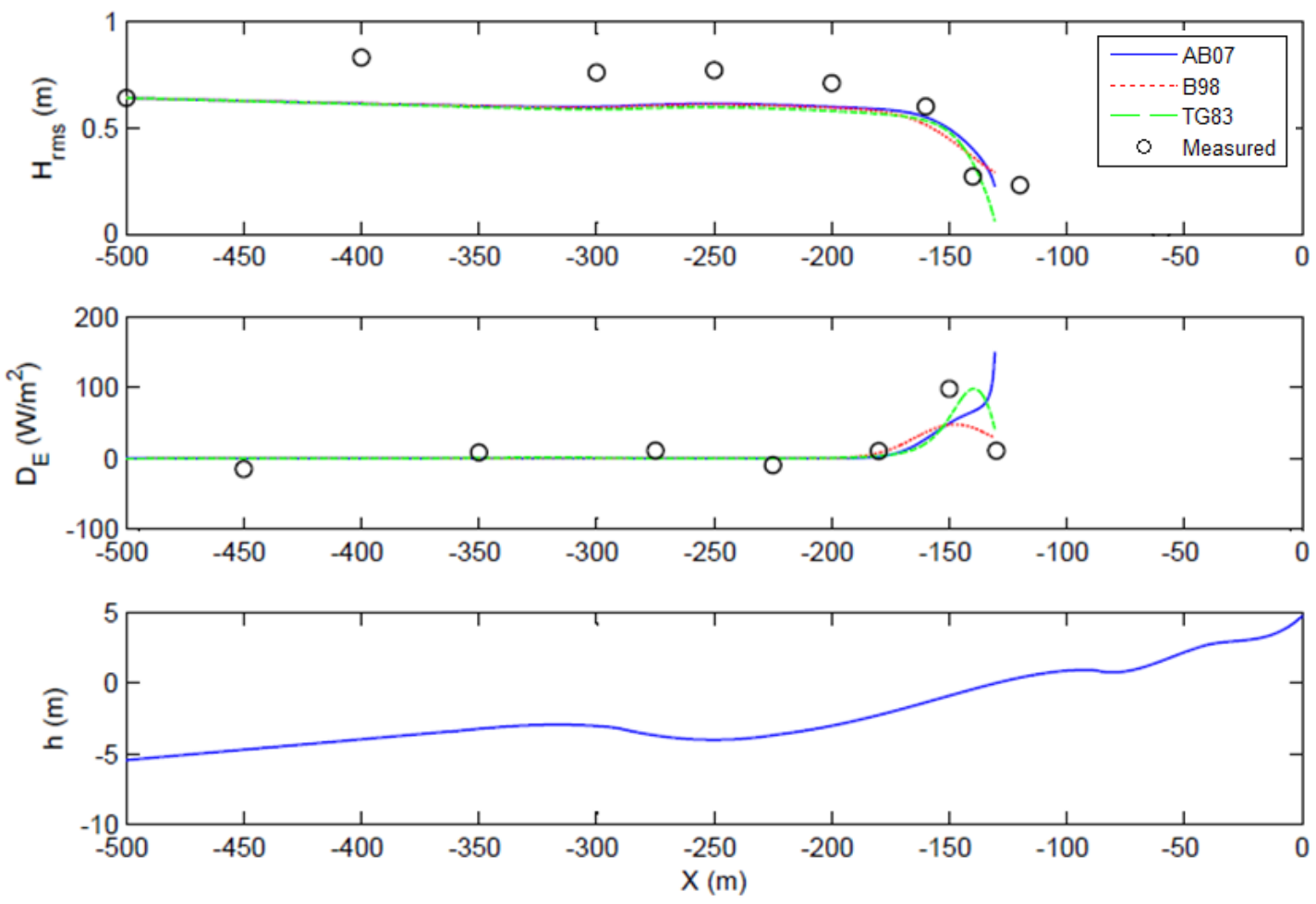

Figure 10. Mild Condition model-data comparison; Top panel is $H_{r m s}$ distribution, 2nd panel is distribution of energy dissipation per unit area and 3rd panel is the bathymetry. Circles represent data; AB07 is the blue line; B98 is the red dotted line and TG83 is the green dash line. 

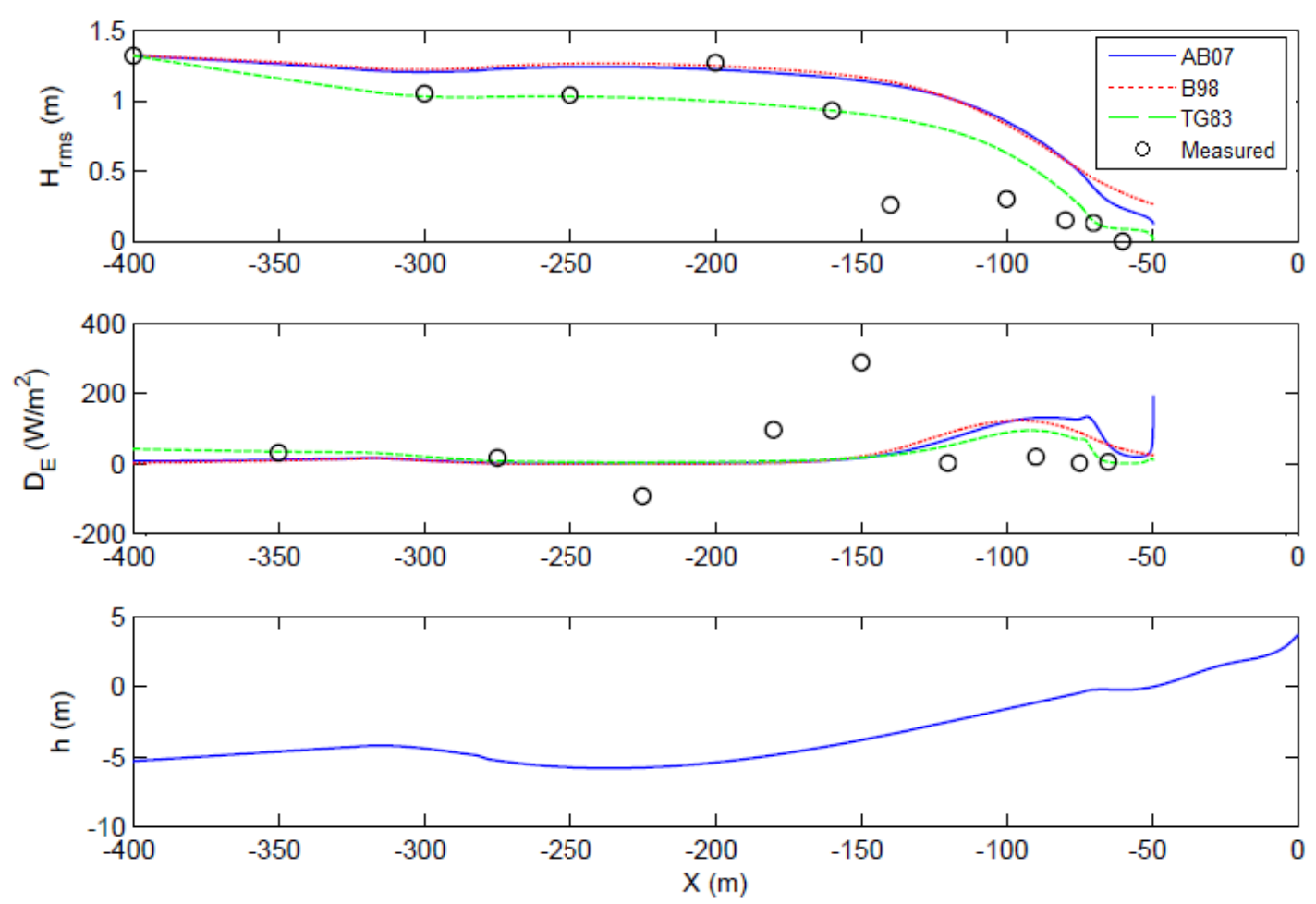

Figure 11. TC Ului model-data comparison; Top panel is $H_{r m s}$ distribution, 2 nd panel is distribution of energy dissipation per unit area and 3rd panel is the bathymetry. Circles represent data; AB07 is the blue line; B98 is the red dotted line and TG83 is the green dash line.

In the TC Ului events, the offshore boundary was set at 400m offshore. As illustrated in Figure 11 the models cannot predict the near shore breaking. Second panel of the Figure 11 clearly shows that the energy dissipation calculated by models at the near shore breaking line $(\mathrm{x}=-150 \mathrm{~m})$ are considerably lower than what field data shows. Also due to numerically calibration of the TG3 model in order to reduce the error, it was shown a better prediction in compare to AB07 and B98. Furthermore, although the AB07 model yields a slightly better result in terms of prediction error rather than B98, the coefficient of determination of the B98 model result is better than what AB07 returns.

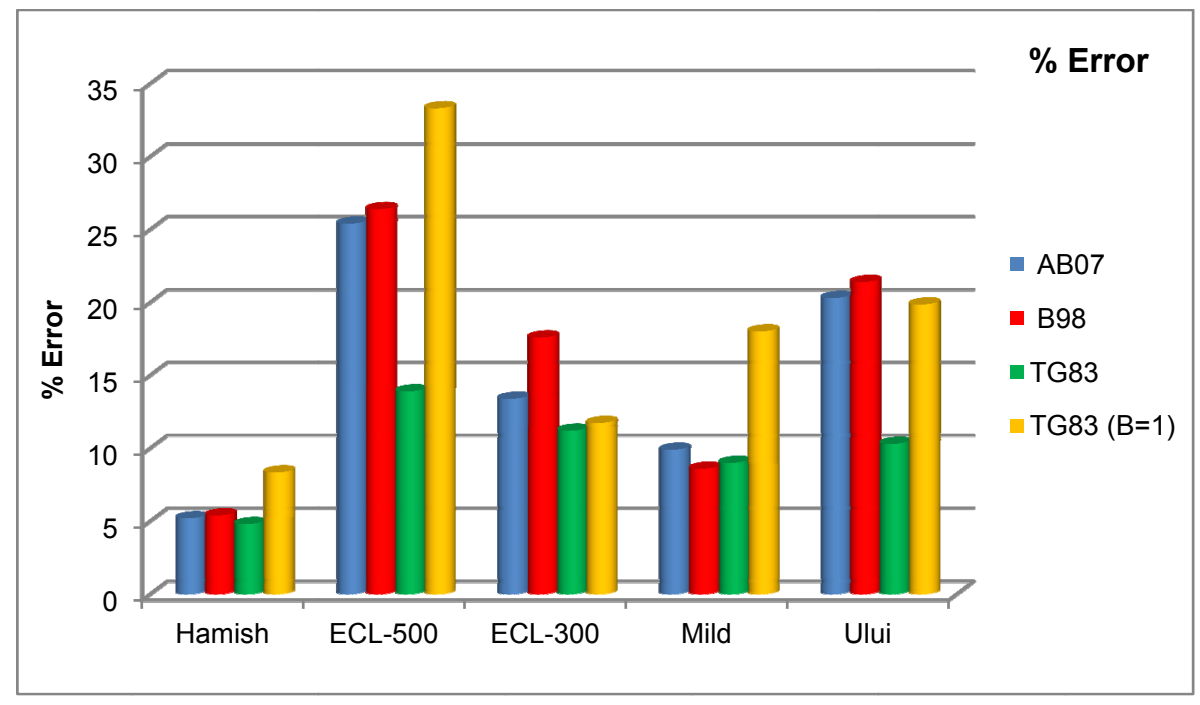

Figure 12. Calculated error of models prediction based on equation (14) against field data 


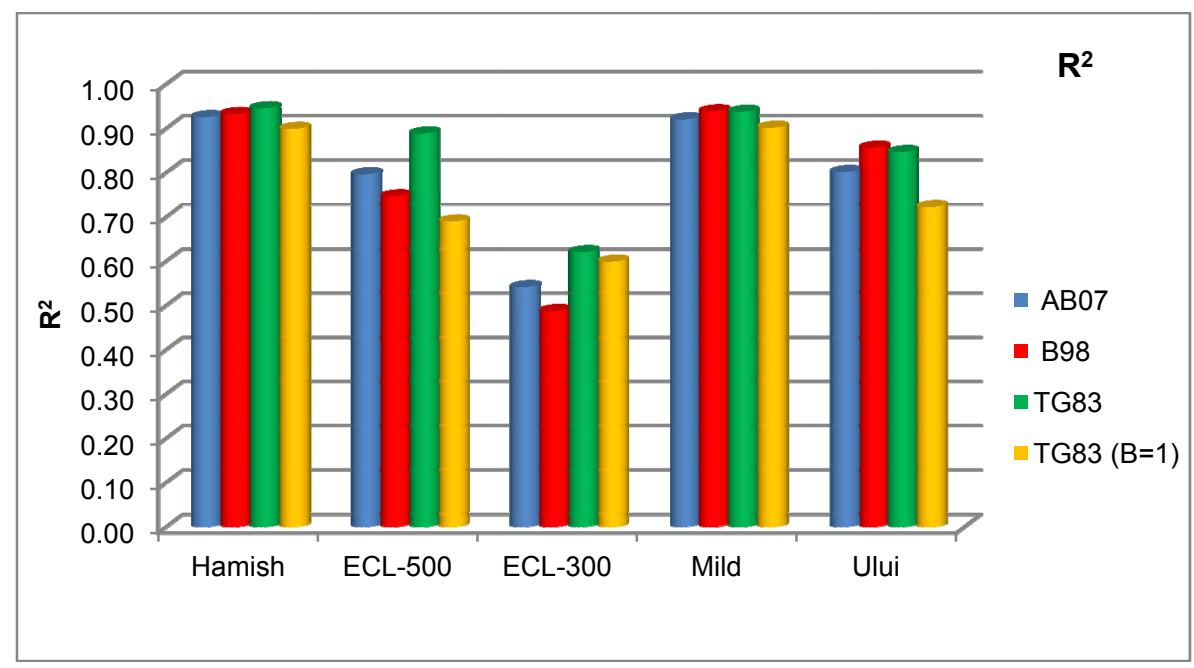

Figure 13. Calculated factor of determination $\left(R^{2}\right)$ of models prediction against field data

The error and $\mathrm{R}^{2}$ of model prediction against field data are presented in Figure 12 and Figure 13 respectively. In order to being fair to all models, the calibration factor, $B$, is also considered as one for the TG83 model and then the error and $\mathrm{R}^{2}$ were recalculated and displayed on Figure 12 and Figure 13. As it shown in these figures, the TG83 model with considering $B$ equal to one generally returned higher errors and a bit less $\mathrm{R}^{2}$.

\section{LABORATORY DATA - MODEL COMPARISON}

\section{Experimental Setup}

Laboratory experimentations were performed on an $8 \mathrm{~m}$ long and $0.5 \mathrm{~m}$ wide wave flume. Waves were generated using an electrically driven wave maker with the ability to produce both regular and irregular waves. A wave absorption system was deployed at the far end of the flume. A Gold Coast beach profile was constructed in the scale of 1:57. In order to capture the high resolution of wave height, 15 Pressure Transducer sensors with accuracy of order $\pm 1 \mathrm{~mm}$ were installed in 12 different points along the flume (see Figure 14). The statistical wave properties were calculated using spectral and zero-up crossing analysis. Incident wave properties were extracted from an offshore sensor, i.e. the first sensor from the left hand side (see Figure 14).
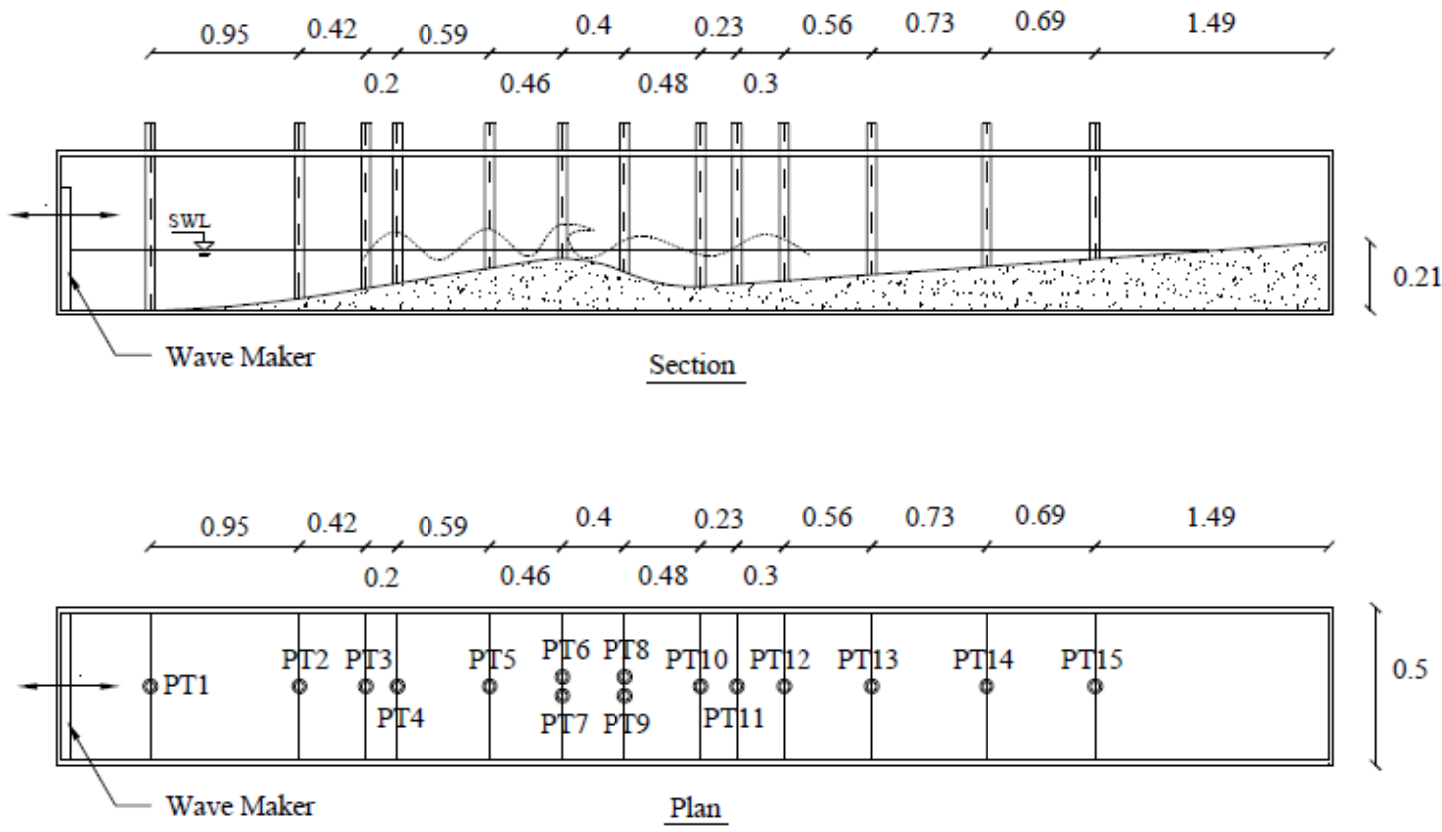
Figure 14.Elevation (top) and plan (bottom) views of the experiment setup in the wave flume. The wave maker is located at the far end of the left side of the flume. The pressure transducer sensor spacing are shown in both the plan and the section views of the wave flume

The bottom profile was surveyed by filling the flume up to $0.215 \mathrm{~m}$, measured at the offshore boundary, and then the profile was measured against the still water level at $0.1 \mathrm{~m}$ intervals along the flume (see Figure 15). The survey was repeated on different days of testing in order to capture any changes. Also a test run was made prior to each experiment in order to find out the approximate breaking points. This information was used to determine the optimal position of the sensors in order to capture the wave breaking with more resolution.

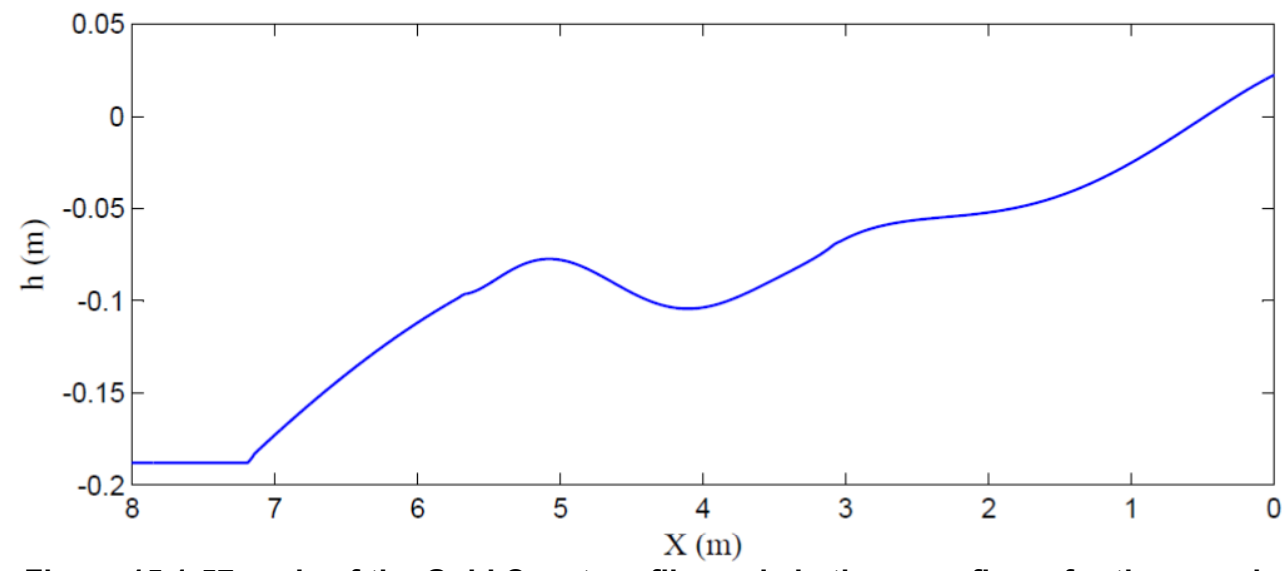

Figure 15.1:57 scale of the Gold Coast profile made in the wave flume for the experiment

The offshore wave height recorded by the first sensor immediately after the wave maker, at a depth of $0.188 \mathrm{~m}$, was defined as the offshore boundary of the model. 36 different wave conditions were generated in this experiment which $H_{r m s}$ varies from $0.02 \mathrm{~m}$ to $0.058 \mathrm{~m}$ and $T_{p}$ varies from $0.623 \mathrm{~s}$ to 4.101s, using JONSWAP spectrum with gamma equal to 3.3 .

\section{Results and Discussion}

For all the test conditions the offshore surf similarity, $\zeta_{0}$, was calculated along with $\mathrm{R}^{2}$ and $\varepsilon$. Results of model prediction against experimental data are plotted versus $\zeta_{\mathrm{o}}$ and presented in Figure 16 and Figure 17. according to Coastal Engineering Manual (2002) $\zeta_{0}$ is defined as a wave breaker type criteria which $\zeta_{\mathrm{o}}$ is less than 0.5 , the breaker type is spilling and for $\zeta_{\mathrm{o}}$ greater than 0.5 , the breaker type would be plunging. Figure 16 clearly illustrated that for $\zeta_{0}$ greater than 0.5 the amount of calculated error in model prediction increases. Also in Figure 17 this fact in confirmed by decreasing the amount of $\mathrm{R}^{2}$ for $\zeta_{\mathrm{o}}$ greater than 0.5 . Hence, based on these results, the bore dissipation theory which deployed in the current parametric energy dissipation models is not good enough to predict the plunging breaker type with high accuracy. Therefore, it is require to consider the plunging breaking dissipation in this type of models. 


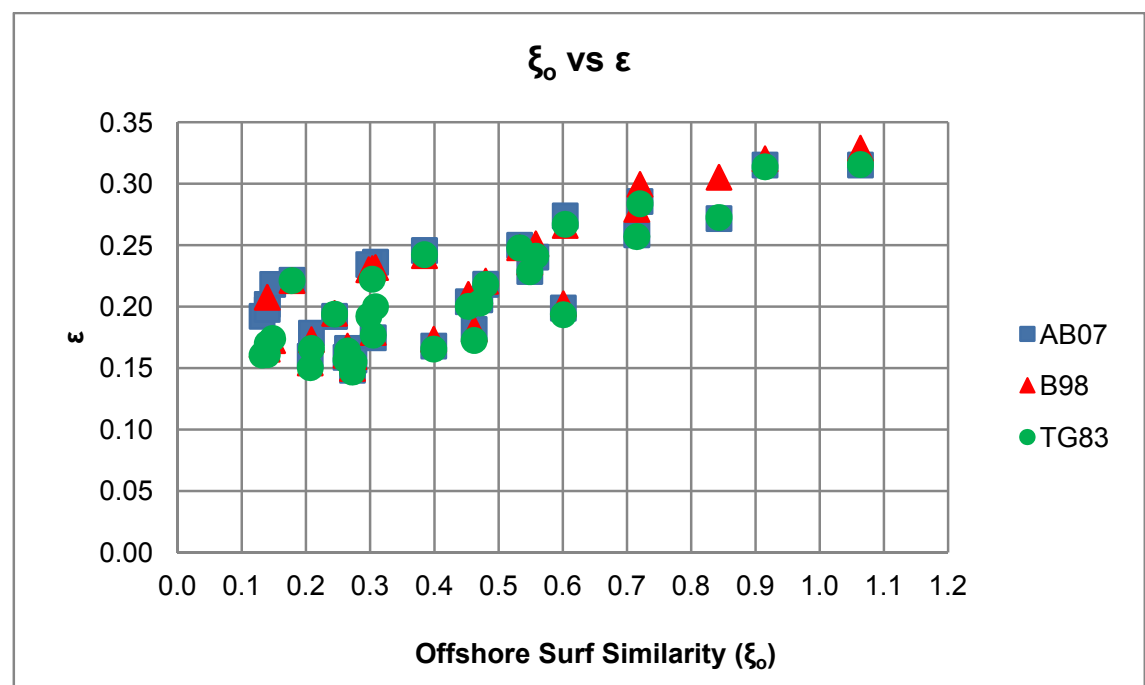

Figure 16. Calculated error of models prediction based on equation (14) against lab data versus $\xi_{0}$

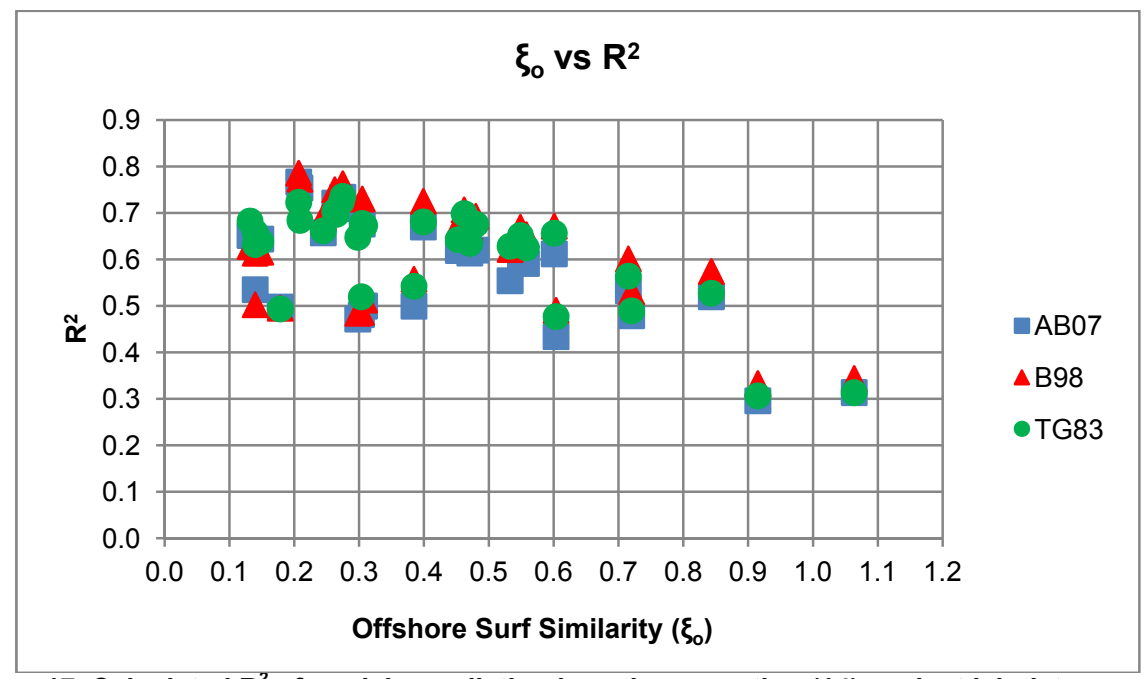

Figure 17. Calculated $R^{2}$ of models prediction based on equation (14) against lab data versus $\xi_{0}$

\section{CONCLUSION}

The parametric wave models result in predicting the wave profile across the surfzone are very precise in the case of swells. Also, in term of choosing a proper model, AB07 and B98 have privilege to TG83 in the cases that no data is available prior to modeling. TG83 leaves two free parameters (i.e. B and $\gamma$ ) in the model in case of calibration based on existing data. Free parameter, "B", in TG83 model numerically improves the results in comparison against the field data (e.g. more than $140 \%$ improvement in $\varepsilon$ in ECL). However, B can be considered as a tuning parameter in AB07 and B98 as well. Moreover, considering the field data comparison, models are not able to capture the sudden energy loss due to plunging breaker. Consequently, plunging dissipation should be considered in order to improve the existing parametric models. Hence, wave energy dissipation due to plunging is going to be considered in the next stage of this research.

\section{REFERENCES}

Alsina, J.M. and Baldock, T.E., (2007). Improved representation of breaking wave energy dissipation in parametric wave transformation models. Coastal Engineering 54 765-769.

Baldock, T.E., Holmes, P., Bunker, S. and Van Weert, P., (1998). Cross-shore hydrodynamics within an unsaturated surf zone. Coastal Engineering, 34: 173-196.

Battjes, J.A. and Janssen, J.P.F.M., (1978). Energy loss and set-up due to breaking of random waves, 16th Int. Conf. on Coastal Engineering ASCE, Hamburg, Germany, pp. 569-587. 
Guard, P.A. and Baldock, T.E., (2007). The influence of seaward boundary conditions on swash zone hydrodynamics. Coastal Engineering, 54(4): 321-331.

Hwang, L.S. and Divoky, D., (1970). Braking wave set up and decay on gentle slopes, In Proceedings of the 12th international conference on coastal engineering pp. 377-389.

Jafari, A., Cartwright, N. and Nielsen, P., (2011). Stormy Wave Analysis Based on Recorded Field Data on South-East Coasts of Queensland, Australia. Journal of coastal Research, SI 64: $527-$ 533.

LeMehaute, (1962). On Non-Saturated Breakers and the Wave Run-Up, 8th International Conference of Coastal Engineering, New York, pp. 77-92.

Nairn, R.B., (1990). Prediction of cross-shore sediment transport and beach profile evolution, University of London, London, England.

Raubenheimer, B., Guza, R.T. and Elgar, S., (1996). Wave transformation across the inner surf zone. Journal of geophysical research, 101: 25,589-25,597.

Ruessink, B.G., Walstraa, D.J.R. and Southgate, H.N., (2003). Calibration and verification of a parametric wave model on barred beaches. Coastal Engineering, 48: 139-149

Thornton, E.B. and Guza, R.T., (1983). Transformation of Wave Height Distribution. Journal of geophysical research, 88: 5925-5938.

US Army Corps Of Engineers, N., (2002). Coastal Engineering Manual. Analysis.

van Rijna, L.C. et al., (2003). The predictability of cross-shore bed evolution of sandy beaches at the time scale of storms and seasons using process-based Profile models. Coastal Engineering, 47(295-327). 